\title{
Urolitíase por cistina em cães no Brasil
}

[Canine cystine urolithiasis in Brazil]

\author{
D.A. Godoi ${ }^{1}$, E. Regazoli ${ }^{2}$, S.E. Beloni ${ }^{2}$, M.S. Zanutto ${ }^{2}$ \\ ${ }^{1}$ Departamento de Clínica Cirúrgica Veterinária - Universidade de São Paulo - USP - São Paulo, SP \\ ${ }^{2}$ Departamento de Clínicas Veterinárias - Universidade Estadual de Londrina - UEL - Londrina, PR
}

\section{RESUMO}

O presente trabalho tem como objetivo relatar três casos de urolitíase canina por cistina, atendidos no Hospital Veterinário da Universidade Estadual de Londrina entre o período de 2007 a 2009. O diagnóstico de urolitíase foi baseado na anamnese, no exame físico e nos exames laboratoriais e radiográficos, e a confirmação do tipo de urólito envolvido foi realizada no Centro de Urólitos de Minnesota-USA, por meio de análise quantitativa, revelando cálculos puros de cistina. A terapia instituída incluiu a remoção cirúrgica dos urólitos e a prevenção de recidivas, por meio do aumento da solubilidade da cistina na urina com dieta comercial própria, aumento da ingestão hídrica e alcalinização medicamentosa da urina.

Palavras-chave: cão, urólito, cistinúria

\begin{abstract}
Three cases of canine cystine urolithiasis were reported at the Veterinary Hospital of Londrina State University in the period from 2007 to 2009. The diagnosis of urolithiasis was based on clinical history, physical examination, laboratory tests and radiographs, and the confirmation of the urolith type was performed at the Minnesota Urolith Center - USA, trough quantitative analysis, showing pure cystine uroliths. The therapy administered in both cases included surgical removal of the uroliths and prevention of recurrence by increasing the solubility of cystine in the urine with a commercial diet, increased fluid intake and alkalinization of the urine.
\end{abstract}

Keywords: dog, urolith, cystinuria

\section{INTRODUÇÃO}

Os urólitos são formados quando ocorre supersaturação da urina por substâncias cristalogênicas, e definidos como um conjunto de material cristalino e matriz orgânica ou inorgânica que se forma no trato urinário. A urolitíase é considerada como a causa e os efeitos dos urólitos no trato urinário (Osborne et al., 1999a; Osborne et al., 2009b; Oyafuso et al., 2010). Os sinais clínicos mais comuns são hematúria, polaciúria, disúria e estrangúria. Os urólitos também podem predispor ao desenvolvimento de infecção do trato urinário (ITU) e, quando alojados nos ureteres ou na uretra, poderá ocorrer obstrução do fluxo urinário (Oyafuso et al., 2010).

A cistinúria em cães é decorrente de um defeito metabólico hereditário que ocorre no túbulo renal, levando à excreção urinária excessiva de cistina e de outros aminoácidos não essenciais. Devido à pouca solubilidade da cistina na urina, pode ocorrer a precipitação e a formação de urólito (Case et al., 1992; Koehler et al., 2009).

A prevalência de urólitos de cistina varia conforme a região. Na Europa, há a maior incidência reportada, podendo representar até $40 \%$ dos urólitos de cães. Nos Estados Unidos a incidência varia de 1 a 4\% (Osborne et al., 1986;

Recebido em 10 de maio de 2010

Aceito em 1 de junho de 2011

E-mail: godoidaniella@gmail.com 
Case et al., 1992; Bartges et al., 1994; Ling et al., 1998; Osborne et al., 1999b). No Brasil, em recente estudo realizado na Universidade de São Paulo, foram analisados 161 urólitos, nos quais não foram constatados urólitos de cistina (Oyafuso et al., 2010).

A cistinúria tipo I encontrada nas raças Newfoundlands e Labrador Retrievers é homóloga à cistinúria tipo I encontrada em humanos com mutações no gene SLC3A1 e caracterizada por formação de urólitos em machos jovens, ocasionalmente em fêmeas com alta excreção urinária de cistina e outros aminoácidos não essenciais. A cistinúria em outras raças é caracterizada pela formação de urólitos em fase tardia da vida do animal, porém não antes da fase adulta com moderada elevação e variada excreção urinária de cistina e outros aminoácidos não essenciais na urina, porém com carga hereditária desconhecida (Casal et al., 1995; Bannasch e Henthorn, 2009; Koehler et al., 2009).

A radiopacidade dos urólitos de cistina é semelhante à dos urólitos de estruvita e sílica, são mais radiolucente do que os de oxalato de cálcio e fosfato de cálcio, e mais radiopacas do que os de urato de amônio e sódio. Os cálculos de cistina podem ser visualizados no exame radiográfico simples, porém precisam estar presentes em tamanho suficiente. Entretanto, o diagnóstico definitivo de urolitíase por cistina é realizado apenas pela análise quantitativa do cálculo (Bovee e Mcguire, 1984; Osborne et al., 1989; Osborne et al., 1995).

O objetivo da terapia é promover a dissolução dos urólitos de cistina e evitar sua recidiva, com a redução da concentração urinária de cistina e aumento de sua solubilidade na urina, por meio da redução de proteína da dieta, alcalinização da urina, aumento da ingestão hídrica do paciente e se necessário, administração de fármacos contendo tiol (2-MPG) (Osborne et al., 1999b; Osborne et al., 2009a).

$\mathrm{O}$ presente artigo tem como objetivo relatar a ocorrência de três casos de urolitíase canina por cistina, bem como discutir a etiopatogenia, o diagnóstico, as possíveis complicações e as medidas terapêuticas clínicas e cirúrgicas desta afecção.

\section{MATERIAIS E MÉTODOS}

Em outubro de 2007 foi atendido, no setor de clínica médica do Hospital Veterinário da Universidade Estadual de Londrina, PR, um cão, da raça Pinscher, de dez anos de idade, pesando $4,6 \mathrm{~kg}$, o qual apresentava estrangúria e anúria há um dia. O proprietário relatou que o animal tinha histórico de urolitíases recorrentes há dois anos, e que foram realizadas quatro cistotomias prévias ao atual atendimento.

Ao exame físico, o animal apresentava parâmetros fisiológicos normais, porém a vesícula urinária estava distendida, e o abdômen tenso à palpação. $\mathrm{O}$ quadro era sugestivo de obstrução uretral por recidiva de urólitos. A radiografia abdominal confirmou a presença de urólitos na bexiga e uretra. Foram realizados hemograma e exames bioquímicos préoperatórios, os quais não mostraram alteração, sendo o animal submetido à intervenção cirúrgica.

Não foi possível a realização da urohidropropulsão dos cálculos presentes na uretra para o interior da bexiga, portanto realizaram-se cistotomia e uretrostomia permanentes no mesmo dia do atendimento, removendo-se cinco cálculos de diversos tamanhos (Fig. 1).

O animal ficou internado durante três dias com prescrição de cefalexina, tramadol, meloxicam e compressa de gelo na ferida cirúrgica. $\mathrm{O}$ quadro evoluiu bem com redução da hematúria e disúria, e o paciente obteve alta hospitalar. Foi indicado ao paciente estímulo à ingestão de água dieta terapêutica comercial para prevenir a formação de novos urólitos.

A análise quantitativa revelou cálculo puro de cistina, e foi adicionado à prescrição citrato de potássio, com o objetivo de alcalinizar a urina como prevenção de recidivas. Realizou-se urocultura, com resultado negativo, e, após três meses o animal retornou ao hospital com episódios de vômitos diários. Realizaram-se hemograma e exames bioquímicos, com resultados sem alterações dignas de nota, cultura da urina, com resultado negativo, e urinálise, considerando-se que a urina estava ácida foi aumentada a dose do citrato de potássio, e prescrito ranitidina. 
Quinze dias após, foram realizados raio-x e ultrassonografia abdominal, observando-se microcálculos na bexiga e rim e na massa pancreática. $\mathrm{O}$ animal foi submetido à anestesia geral para biópsia aspirativa e veio a óbito durante o procedimento.

Em novembro de 2007, um segundo cão, Mastif inglês, de cinco anos de idade, com $67 \mathrm{~kg}$, foi atendido no setor de clínica médica no Hospital Veterinário da UEL-PR, com quadro de disúria e polaquiúria, com evolução de 20 dias. Ao exame físico, foram constatadas mucosas congestas, leve hipertermia $\left(39,4^{\circ} \mathrm{C}\right)$, taquicardia e taquipneia. Ao exame radiográfico, observou-se a presença de um cálculo vesical radiopaco com $2,2 \mathrm{~cm}$ de diâmetro. $\mathrm{O}$ animal foi anestesiado e foi realizada sondagem uretral, urohidropropulsão e lavagem vesical, sendo removidos quatro pequenos cálculos uretrais.

Foram realizados exames complementares: urinálise, creatinina sérica e urocultura. A creatinina apresentou leve aumento $(1,65 \mathrm{mg} / \mathrm{dL})$, a urinálise revelou a presença de cristalúria por cistina (Fig. 1) e aumento da celularidade (hematúria e piúria). Na urocultura, houve crescimento bacteriano de Serratia spp e, no antibiograma, a bactéria foi sensível à enrofloxacina, norfloxacina e sulfazotrin.

No dia seguinte ao atendimento, o animal foi submetido à cistotomia para a retirada do cálculo vesical. Foram encontrados vários microcálculos e um cálculo de $2 \mathrm{~cm}$ de diâmetro na entrada da uretra (Fig. 1). Realizou-se lavagem vesical com solução fisiológica, sendo inserida a sonda de forma normógrada e retrógrada. O antibiótico administrado no pós-operatório foi cefalexina, como no primeiro relato, porém foi trocado por enrofloxacina, de acordo com o resultado do antibiograma. Os cálculos retirados foram enviados ao Centro de Urólitos de MinnesotaUSA, para análise quantitativa, os quais resultaram em urólitos puros de cistina.

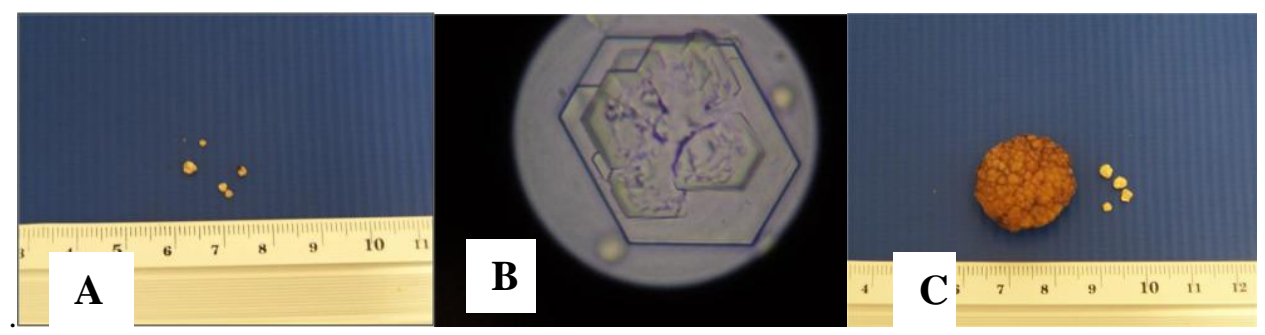

Figura 1. A: Urólito de cistina do primeiro cão. B: Fotomicrocrafia de sedimento urinário, evidenciando cristais de cistina achatados, incolores e hexagonais na urina do primeiro cão (objetiva de 100X). C: Urólitos de cistina do segundo cão.

O animal ficou internado durante dois dias, com prescrição de cefalexina, tramadol e cetoprofeno. O quadro evoluiu bem com redução da hematúria e disúria, e o paciente obteve alta hospitalar. O tratamento pós-operatório foi semelhante ao do primeiro animal, a exceção do citrato de potássio, que não foi prescrito, pois o animal apresentava urina alcalina.

Após 45 dias da cirurgia, o animal voltou a apresentar obstrução uretral, retornou ao hospital com quadro de polaquiúria, micção em gotas e hiporexia, com dois dias de evolução. Foram realizados hemograma e exames bioquímicos, cuja única alteração foi aumento no nível sérico de creatinina $(2,41 \mathrm{mg} / \mathrm{dL})$. $\mathrm{O}$ animal foi sedado e realizada novamente cistotomia para remoção de urólitos, sendo removidos cinco cálculos de aproximadamente $1 \mathrm{~cm}$ de diâmetro. $\mathrm{O}$ animal ficou internado durante dois dias e teve alta com a prescrição de enrofloxacina.

Um mês após a segunda cirurgia, o animal retornou em bom estado geral. Realizaram-se urinálise e urocultura, revelando $E$. coli, sensível à norfloxacina, que foi prescrita, juntamente com ração terapêutica própria para urolitíase por cistina e estimulo ao aumento da ingestão hídrica.

Nos oito meses seguintes, foram realizadas urinálises e uroculturas controle, que revelaram 
infecções urinárias recorrentes, as quais foram tratadas de acordo com antibioticoterapia baseada no antibiograma.

Nove meses após a segunda cirurgia, o animal retornou ao pronto-atendimento do Hospital Veterinário com quadro de obstrução uretral e foi encaminhado para cirurgia de cistotomia e uretrostomia permanente pré-escrotal. Foi removido um cálculo de aproximadamente $5 \mathrm{~mm}$ de diâmetro na base do osso peniano.

O animal ficou internado, com sonda uretral, durante 10 dias, e com prescrição de amoxacilina com clavulanato, tramadol e meloxicam. Após a redução da hematúria, a sonda foi removida, e o paciente obteve alta hospitalar.

O animal sofre controle ultrassonográfico a cada três meses e urinálise mensal, e encontra-se há dezoito meses sem recidiva de formação de urólitos.

Em abril de 2009, um terceiro cão, sem raça definida, de dez anos de idade, $13 \mathrm{~kg}$ foi atendido no pronto-atendimento cirúrgico do Hospital Veterinário da UEL com quadro de anúria, com evolução de três dias. Ao exame físico, o animal estava em decúbito lateral, e foram constatadas mucosas congestas, leve hipotermia $\left(37,6^{\circ} \mathrm{C}\right)$, desidratação leve e bexiga distendida. $\mathrm{O}$ animal foi submetido à sondagem uretral e constatou-se obstrução do fluxo urinário. Ao exame radiográfico, observou-se a presença de um cálculo na uretra peniana. $\mathrm{O}$ animal foi monitorado intensivamente e foram removidos $330 \mathrm{ml}$ de urina por meio de cistocentese e, após seis horas, removidos mais $440 \mathrm{~mL}$ de urina.

A creatinina apresentou severo aumento $(7,68 \mathrm{mg} / \mathrm{dL})$, a urinálise revelou hemoglobinúria, bilirrubinúria, cristalúria por oxalato de cálcio e bilirrubina, além de aumento da celularidade (hematúria). Não houve crescimento bacteriano na urocultura.

Após 12 horas do atendimento, o animal foi anestesiado e submetido à uretrotomia para a remoção dos cálculos. Foram encontrados quatro cálculos uretrais menores que $0,5 \mathrm{~cm}$ de diâmetro e um cálculo de aproximadamente $1 \mathrm{~cm}$ de diâmetro na uretra peniana. Realizou-se lavagem uretral e vesical com solução fisiológica, e o animal foi mantido com sonda uretral após o procedimento. Os cálculos removidos foram enviados ao Centro de Urólitos de MinnesotaUSA, para análise quantitativa, resultando em urólitos puros de cistina

No dia seguinte ao procedimento cirúrgico, o animal estava alerta e a sonda foi retirada. O paciente recebeu tratamento pós-operatório semelhante ao utilizado no primeiro animal.

O animal retornou após dez dias da cirurgia, em bom estado geral, para remoção dos pontos e, após um mês do procedimento, retornou para nova reavaliação. Os exames complementares, incluindo hemograma completo, urinálise, ureia e creatinina sérica, foram repetidos e não apresentaram alterações dignas de nota. $\mathrm{O}$ proprietário não compareceu no retorno programado para 60 dias e, após um ano do atendimento inicial, ele relatou que o animal não apresentou recidiva do quadro, mesmo sem qualquer acompanhamento e tratamento.

\section{DISCUSSÃO}

Os cálculos de cistina acarretaram inflamação do trato urinário e obstrução urinária, com o segundo e o terceiro animais apresentando azotemia por curto período. Os urólitos podem lesar o uroepitélio, resultando em inflamação do trato urinário e, quando encontram-se alojados nos ureteres ou na uretra, podem ocorrer obstrução uretral e azotemia por períodos curtos ou durante toda a vida do paciente (Grauer, 2003; Bannasch e Henthorn, 2009).

Apesar de a cistinúria ser decorrente de um erro metabólico hereditário, os animais avaliados apresentaram sinais clínicos quando adultos. Segundo a literatura, os urólitos de cistina não são comuns em animais muito jovens (Bartges et al., 1994; Osborne et al., 1999b).

Como observado no presente trabalho e citado na literatura, urólitos de cistina ocorrem predominantemente em machos e se manifestam em diversas raças, sendo as mais acometidas, segundo o Centro de Urólitos de MinnesotaUSA, Buldogue Inglês (18\%), Dachshund (6\%), Staffordshire Bull Terriers (6\%), Mastiff (6\%), Chihuahuas $(5 \%)$ e dentre aquelas sem definição racial (6\%) (Osborne et al., 1986; Osborne et al., 1999b). 
A urinálise foi de grande importância diagnóstica no segundo cão, pois segundo Osborne et al. (1999b), os cristais de cistina não estão constantemente presentes em cães com cistinúria ou com urólitos de cistina, e a detecção destes cristais confirma o diagnóstico de cistinúria.

A recidiva após a remoção cirúrgica foi observada nos casos um e dois, e por tratar-se de um defeito metabólico, os urólitos de cistina frequentemente recidivam. Portanto, a terapia profilática deve ser instituída. As recomendações para o tratamento de urólitos de cistina consistem em reduzir a concentração urinária de cistina e aumentar a solubilidade desse aminoácido na urina, por meio da redução proteica da dieta, da alcalinização da urina e, se necessário, da administração de fármacos contendo tiol (Osborne et al., 1999b; Adams e Syme, 2005; Oyafuso et al., 2010).

O tiol (N-(2mercaptopropionilglicina)) ou 2MPG não foi associado ao tratamento dos casos relatados, pois o fármaco não se encontra disponível no Brasil. Este fármaco diminui a concentração de cistina por uma reação de troca de dissulfeto do tiol, resultando em um composto mais solúvel na urina, o dissulfeto de cisteína-2MPG (Hoppe et al., 1993; Osborne et al., 2003).

Em todos os casos, foram recomendadas dietas comerciais e redução da proteína, especialmente os alimentos ricos em metionina, o precursor da cistina, pois, além de diminuir a excreção de cistina, reduz a concentração medular de ureia, levando a uma diminuição da concentração urinária e também à produção de urina menos ácida (Adams e Syme, 2005). Dietas comerciais próprias para doenças do trato urinário reduzem a excreção de cistina, promovem a alcalinização da urina e reduzem a densidade urinária (Osborne et al., 2003).

No primeiro cão, foi instituída terapia com citrato de potássio na tentativa de alcalinizar a urina, pois a solubilidade urinária da cistina é dependente do $\mathrm{pH}$. As mudanças no $\mathrm{pH}$ urinário que permaneçam no patamar ácido não apresentam efeitos na solubilidade da cistina. Em cães, a solubilidade da cistina na urina com $\mathrm{pH}$ 7,8 é aproximadamente o dobro quando comparada com solubilidade na urina com $\mathrm{pH}$ 5,0 (Osborne et al., 1999b). Portanto, na condição em que a urina não estiver suficientemente alcalina por meio da dieta terapêutica, recomenda-se a administração de citrato de potássio (40 a 75mg/kg PO BID) para manter o $\mathrm{pH}$ urinário próximo de 7,5. Entretanto, a alcalinização da urina é um fator de risco para a formação de urólitos de fosfato de cálcio e para as infecções bacterianas (Osborne et al., 1999b; Osborne et al., 2003).

Apesar de recidivas frequentes, o terceiro cão não apresentou formação de novos urólitos, e o segundo cão encontra-se há um ano e meio sem recidiva. A literatura menciona que provavelmente existam populações de cães cistinúricos com diferentes taxas de recidiva de urólitos independente da medicação. Alguns cães apresentam baixa capacidade de formar urólitos, devido a fatores desconhecidos, e não necessitam de medicação, enquanto outros cães apresentam recidivas diminuindo com o passar do tempo, resultando no fato de que, com o controle adequado, os pacientes cistinúricos apresentam sobrevida longa (Case et al., 1992; Osborne et al., 2003).

\section{CONCLUSÕES}

A incidência de urólitos de cistina no Brasil não é ainda conhecida, sendo esses os primeiros relatos. A colaboração do proprietário é essencial no tratamento de pacientes cistinúricos, pois são pacientes que necessitam de monitoração e cuidados constantes com a finalidade de evitar recidivas.

\section{REFERÊNCIAS BIBLIOGRÁFICAS}

ADAMS, L.G.; SYME, H.M. Canine lower urinary tract diseases. In: ETTINGER, S.J.; FELDMAN, E.C. Textbook of veterinary internal medicine. 6.ed.St. Louis: ELSEVIER, 2005. p.1850-1874.

BANNASCH, D; HENTHORN, P.S. Changing paradigms in diagnosis of inherited defects associated with urolithiasis. Vet. Clin. N. Amer.: Small Anim. Pract., v.39, p.111-125, 2009.

BARTGES, J.W.; OSBORNE, C.A.; LULICH, J.P. et al. Prevalence of cystine and urate uroliths in Bulldogs and urate uroliths in Dalmatians. $J$. Am. Vet. Med. Assoc., v.204, p.1914-1918, 1994. 
BOVEE, K.C.; MCGUIRE, T. Qualitative and quantitative analysis of uroliths in dogs: definitive determination of chemical type. J. Am. Vet. Med. Assoc., v.185, p.983-987, 1984.

CASAL, M.L.; GIGER, U.; BOVEE, K.C. et al. Inheritance of cystinuria and renal defect in Newfoundlands. J. Am. Vet. Med. Assoc., v.207, p.1585-1589, 1995.

CASE, L.C.; LING, G.V.; FRANTI, C.E. et al. Cystine-containing urinary calculi in dogs: 102 cases (1981-1989). J. Am. Vet. Med. Assoc., v.201, p.129-133, 1992.

GRAUER, G.F. Canine Urolithiasis. In: NELSON, R.W.; COUTO, C.G. Small Anim. Int. Med. 3.ed. St Louis: MOSBY, 2003. p. 631-641.

HOPPE, A.; DENNEBERG, T.; JEPSSON, J.O. et al. Canine cystinuria: An extended study on the effects of 2-mercaptopropionylglycine on cystine urolithiasis and urinary cystine excretion. Brit. Vet. J., v.149, p.235-251, 1993.

KOEHLER, L.A.; OSBORNE, C.A.; BUETTNER, M.T. et al. Canine uroliths: Frequently asked questions and their answers. Vet. Clin. N. Amer.: Small Anim. Pract., v.39, p.161-181, 2009.

LING, G.V.; FRANTI, C.E.; RUBY, A.L. et al. Urolithiasis in $\operatorname{dogs}$ I: Mineral prevalence and interrelations of mineral composition, age, and sex. Am. J. Vet. Res., v.59, p.624-629, 1998.

OSBORNE, C.A.; CLINTON, C.W.; BAMMAN, L.K. et al. Prevalence of canine uroliths. Vet. Clin. N. Amer.: Small Anim. Pract., v.16, p.27-44, 1986.

OSBORNE, C.A.; LULICH, J.P.; FORRESTER, D. et al. Paradigm changes in the role of nutrition for the management of canine and feline urolithiasis. Vet. Clin. N. Amer.: Small Anim. Pract., v.39, p.127-141, 2009a.
OSBORNE, C.A.; LULICH, J.P.; KRUGER, J.M. et al. A. Analysis of 451.891 canine urolhits, feline urolthis, and feline urethral plugs from 1981 to 2007: Perspectives from the Minnesota Urolith Center. Vet. Clin. N. Amer.: Small Anim. Pract., v.39, p.183-197, 2009b.

OSBORNE, C.A.; LULICH, J.P.; POLZIN, D.J. et al. Analysis of 77.000 canine uroliths. Perspectives from the Minnesota Urolith Center. Vet. Clin. N. Amer.: Small Anim. Pract., v.29, p.17-38, 1999a.

OSBORNE, C.A.; LULICH, J.P., ULRICH, L. Cystine urolithiasis. In: TILLEY, L.P.; SMITH Jr., F.W.K. The 5-minute veterinary consult: canine and feline. 3.ed. Philadelphia: LIPPINCOTT WILLIAMS \& WILKINS, 2003. p. 1307.

OSBORNE, C.A.; LULICH, J.P.; UNGER, L.K. Canine and feline urolithiasis: Relationship of etiopathogenesis to treatment and prevention. In: OSBORNE, C.A.; FINCO, D.R. Canine and feline nephrology and urology. 2.ed. Baltimore: WILLIAMS \& WILKINS, 1995, p.798-888.

OSBORNE, C. A.; POLZIN, D. J., LULICH, J. P. et al. Relationship of nutritional factors to the cause, dissolution, and prevention of canine uroliths. Vet. Clin. N. Amer.: Small Anim. Pract., v.19, p.583-619, 1989.

OSBORNE, C.A.; SANDERSON, S.L.; LULICH, J.P. et al. Canine cystine urolithiasis. Cause, detection, treatment, and prevention. Vet. Clin. N. Amer.: Small Anim. Pract., v.29, p.193211, 1999b.

OYAFUSO, M.K.; KOGIKA, M.M.; WAKI, M.M.; PROSSER, C.S. et al. Urolitíase em cães: avaliação quantitativa da composição mineral de 156 urólitos. Cienc. Rural, v.40, p.102-108, 2010. 